\title{
GAMBARAN PERILAKU HIDUP BERSIH DAN SEHAT (PHBS) SEKOLAH PADA SISWA KELAS AKSELERASI DI SMPN 8 MANADO
}

\author{
${ }^{1}$ Mohamad Julrisam Gomo \\ ${ }^{2}$ Jootje M. L. Umboh \\ ${ }^{2}$ A. J. Pandelaki
${ }^{1}$ Kandidat Skripsi Fakultas Kedokteran Universitas Sam Ratulangi Manado
${ }^{2}$ Bagian Ilmu Kedokteran Masyarakat Fakultas Kedokteran Universitas Sam Ratulangi
Manado

\begin{abstract}
Program Clean and Healthy Behavior (PHBS) is a government program launched in 2006 which aims to change people's behavior is not healthy to be healthy. Basic research in the School PHBS eight indicators of research are: wash hands with running water and soap, using latrines clean and healthy, exercise regularly and measurable, eradicate mosquito larvae, do not smoke at school, weigh and measure the height of each 6 months, dispose of garbage in its place. The purpose of this study was to determine the picture of student acceleration PHBS in SMPN 8 Manado. This study is descriptive conducted in December 2011 - January 2012. Target population in this study were all students acceleration A and B which amounts to 56 students. The sampling method used is the total population and the number of samples 56 students. The results showed that students' knowledge SMP acceleration PHBS 8 Manado to school is good, where $90.4 \%$ of students are aware of the PHBS school. Students' attitudes toward acceleration PHBS Manado SMPN 8 school is good, where 89\% agreed to the concept of school PHBS. Measures students acceleration PHBs SMPN 8 Manado against the school is good, with 68\% of the students practice their knowledge.
\end{abstract}

Keywords: Clean and Healthy Behavior (PHBS), Knowledge, Attitude, Action.

\begin{abstract}
Abstrak: Program Perilaku Hidup Bersih dan Sehat (PHBS) adalah program pemerintah yang diluncurkan pada tahun 2006 dimana bertujuan untuk mengubah perilaku masyarakat yang tidak sehat agar menjadi sehat. Dasar penelitian PHBS Sekolah berada dalam 8 indikator penelitian yaitu : mencuci tangan dengan air yang mengalir dan sabun, menggunakan jamban yang bersih dan sehat, olahraga yang teratur dan terukur, memberantas jentik nyamuk, tidak merokok di sekolah, menimbang berat badan dan mengukur tinggi badan setiap 6 bulan, membuang sampah pada tempatnya. Tujuan dari penelitian ini adalah untuk mengetahui gambaran PHBS siswa akselerasi di SMPN 8 Manado. Penelitian ini bersifat deskriptif yang dilakukan pada bulan Desember 2011 - Januari 2012. Populasi target pada penelitian ini adalah seluruh siswa akselerasi A dan B yang berjumlah 56 siswa. Metode pengambilan sampel yang digunakan yaitu total populasi dan jumlah sampelnya 56 siswa. Hasil penelitian menunjukan bahwa pengetahuan siswa akselerasi SMPN 8 Manado terhadap PHBS sekolah adalah baik, dimana 90,4\% siswa mengetahui akan PHBS sekolah. Sikap siswa akselerasi SMPN 8 Manado terhadap PHBS sekolah adalah baik, dimana 89\% setuju terhadap konsep PHBS sekolah. Tindakan siswa akselerasi SMPN 8 Manado terhadap PHBS sekolah adalah baik, dengan 68\% siswa mempraktekan pengetahuan mereka
\end{abstract}

Kata kunci: PHBS, Pengetahuan, Sikap, Tindakan. 
Sehat adalah hak asasi setiap manusia. Sehat juga merupakan karunia Tuhan yang harus disyukuri, sebab dengan kesehatan segalanya akan tampak indah serta tanpa kesehatan segalanya akan sia-sia. Kondisi sehat dapat dicapai bila mengubah perilaku dari yang tidak sehat menjadi perilaku sehat dan menciptakan lingkungan sekolah yang sehat. Institusi pendidikan dipandang sebagai sebuah tempat yang strategis untuk mempromosikan kesehatan sekolah juga merupakan institusi yang efektif untuk mewujudkan pendidikan kesehatan, dimana peserta didik dapat diajarkan tentang maksud perilaku sehat dan tidak sehat serta konsekuensinya. Selain itu, usia sekolah (termasuk kelompok usia dini) merupakan masa keemasan untuk menanamkan nilai-nilai PHBS dan berpotensi sebagai agent of change untuk mempromosikan PHBS baik di lingkungan sekolah, keluarga, maupun masyarakat. ${ }^{1}$ PHBS di Sekolah adalah upaya untuk memberdayakan siswa, guru, dan masyarakat lingkungan sekolah agar tahu, mau, dan mampu mempraktikkan perilaku hidup bersih dan sehat serta berperan aktif dalam mewujudkan Sekolah Sehat. $^{2}$

SMPN 8 Manado yaitu satu-satunya SMP yang berstatus negeri yang ada di Malalayang. SMPN 8 juga memiliki kelas akselerasi/kelas unggulan di sekolahnya yang menjadi panutan bagi siswa-siswi kelas reguler yang dimana tingkat pengetahuan mereka diatas rata-rata. Hasil penelitian yang di lakukan menunjukkan bahwa siswa kelas akselerasi sebagian besar berada pada kategori sangat matang, ${ }^{3}$ sedangkan siswa program reguler mempunyai tingkat kematangan karier dalam kategori kurang matang. Dengan demikian tingkat pengetahuan siswa kelas akselerasi lebih tinggi dibanding dengan siswa reguler, sehingga bisa dikatakan terdapat perbedaan tingkat kematangan karier siswa kelas akselerasi dengan siswa kelas reguler.

\section{METODE PENELITIAN}

Desain penelitian ini besifat "Deskriptif" mengenai tingkat Perilaku
Hidup Bersih dan Sehat (PHBS) sekolah pada siswa di kelas akselerasi SMPN 8 Manado. Populasi yang digunakan dalam penelitian ini adalah seluruh siswa-siwi di kelas akselerasi yang bejumlah 56 orang. Sampel penelitian ini adalah seluruh populasi (Total Populasi ).

\section{HASIL}

Tabel 1. Distribusi Responden Siswa SMPN 8 Malalayang Berdasarkan Kelas

\begin{tabular}{ccc}
\hline Kelas & Jumlah Siswa & \% \\
\hline Akselerasi A & 27 & 48,2 \\
Akselerasi B & 29 & 51,8 \\
\hline Total & 56 & 100 \\
\hline
\end{tabular}

Dapat dilihat pada Tabel 1, bahwa responden yang paling banyak ialah kelas Akselerasi B dengan 29 siswa (51,8\%) dan diikuti kelas Akselerasi A dengan 27 siswa (48,2\%). Hal ini disebabkan karena jumlah siswa kelas Akselerasi B yang terdaftar di SMPN 8 Manado adalah yang terbanyak yakni 29 siswa.

Tabel 2. Distribusi responden menurut jenis kelamin

\begin{tabular}{ccc}
\hline Jenis Kelamin & Jumlah & $\mathbf{\%}$ \\
\hline Laki - laki & 21 & 37,5 \\
Perempuan & 35 & 62,5 \\
\hline Total & 56 & 100 \\
\hline
\end{tabular}

Dari tabel diatas, dapat dilihat jenis kelamin responden laki-laki berjumlah 21 siswa (37,5\%) dan jumlah responden perempuan berjumlah 35 siswa (62,5\%).

Tabel 3. Distribusi responden menurut umur

\begin{tabular}{cccccc}
\hline Kelas & \multicolumn{3}{c}{ Umur ( Tahun ) } & Jumlah & \% \\
\cline { 2 - 4 } & $10-11$ & $12-13$ & $13-14$ & & \\
\hline $\begin{array}{c}\text { Akselerasi } \\
\text { A }\end{array}$ & 12 & 15 & 0 & 27 & 48,2 \\
$\begin{array}{c}\text { Akselerasi } \\
\text { B }\end{array}$ & 1 & 27 & 1 & 29 & 51,8 \\
\hline Total & $13(23,2 \%)$ & $42(75 \%)$ & $1(1,8 \%)$ & 56 & 100 \\
\hline
\end{tabular}


Berdasarkan Tabel diatas, jumlah responden yang paling banyak adalah kelompok umur 12 - 13 tahun sebanyak 42 siswa dan presentase sebesar (75\%).

\section{Gambaran pengetahuan}

Untuk pengetahuan responden, dari hasil skoring yang didapatkan yaitu 405, maka di gunakan skoring penilaian pengetahuan berdasarkan Guttman: 0-224=Buruk, 225-448=Baik.

Dapat di simpulkan untuk pengetahuan siswa akselerasi SMPN 8 Manado tentang PHBS sekolah adalah baik.

\section{Gambaran sikap}

Untuk sikap responden, dari hasil skoring yang didapatkan yaitu 399, maka di gunakan skoring penilaian sikap berdasarkan Guttman: 0-224=Buruk, 225-448=Baik.

Dapat di simpulkan untuk sikap siswa akselerasi SMPN 8 Manado tentang PHBS sekolah adalah baik.

\section{Gambaran tindakan}

Untuk tindakan responden, dari hasil skoring yang didapatkan yaitu 304, maka di gunakan skoring penilaian tindakan berdasarkan Guttman: 0-224=Buruk, 225-448=Baik.

Dapat di simpulkan untuk tindakan siswa akselerasi SMPN 8 Manado tentang PHBS sekolah adalah baik.

\section{BAHASAN}

Dari hasil penelitian yang dilakukan dapat dilihat bahwa PHBS sekolah siswasiswi kelas akselerasi di SMPN 8 Manado adalah baik. SMPN8 sudah menerapkan PHBS sekolah secara maksimal sesuai dengan tujuan dari promosi kesehatan yaitu untuk membantu masyarakat mengenali dan mengetahui masalahnya sendiri terutama dalam hal kesehatan. ${ }^{4}$ Penelitian ini mendukung penelitian sebelumnya yang telah dilakukan oleh Dennis tentang Gambaran PHBS siswa SMP advent kota Manado yang menyatakan bahwa siswa SMP advent yaitu masuk dalam kategori baik. ${ }^{5}$

Disimpulkan bahwa perilaku seseorang atau masyarakat tentang kesehatan ditentukan oleh pengetahuan, sikap, kepercayaan, tradisi dan sebagainya dari orang atau masyarakat yang bersangkutan. Disamping itu ketersediaan fasilitas, sikap dan perilaku para petugas kesehatan terhadap kesehatan juga akan mendukung dan memperkuat terbentuknya perilaku. $^{6}$

\section{SIMPULAN}

1. Gambaran PHBS pada siswa kelas akselerasi SMPN 8 Manado yaitu baik.

2. Pengetahuan siswa kelas akselerasi SMPN 8 Manado tentang PHBS sekolah, adalah baik.

3. Sikap siswa kelas akselerasi SMPN Manado tentang PHBS sekolah, adalah baik

4. Tindakan siswa kelas akselerasi SMPN 8 Manado tentang PHBS sekolah, adalah baik.

\section{DAFTAR PUSTAKA}

1. Ony L. Praktik perilaku hidup bersih dan sehat (PHBS) pada peserta pendidikan anak usia dini (PAUD) di Kecamatan Koja, Jakarta Utara Tahun 2010. Universitas Muhamadiyah Prof.DR.Hamka.

2. Promosi Kesehatan Di Sekolah. Pusat Promosi Kesehatan Departemen Kesehatan Republik Indonesia 2007.

3. Raudhah. Perbedaan kematangan karier siswa kelas akselerasi dengan siswa kelas reguler SMAN 3 Malang [Tesis]. Malang: Universitas Negeri Malang; 2010.

4. Prastianingsih Y. Perbedaan tingkat perilaku hidup bersih dan sehat (PHBS) di Sekolah Dasar dan Sekolah Dasar Swasta di Kecamatan Kenjeran. Surabaya: Universitas Muhammadiyah

5. Rantung D. Gambaran Perilaku Hidup Bersih dan Sehat siswa SMP Advent Kota Manado [Skripsi]. Manado: FK Universitas Sam Ratulangi; 2011.

6. Notoatmojo S. Pendidikan dan Perilaku Kesehatan. Jakarta: Rineka Cipta; 2003. 